\title{
Rectal Necrotic Lesion
}

National Cancer Institute

\section{Source}

National Cancer Institute. Rectal Necrotic Lesion. NCI Thesaurus. Code C78585.

A necrotic process involving the rectal wall. 